\title{
Withaferin A inhibits the proliferation of gastric cancer cells by inducing G2/M cell cycle arrest and apoptosis
}

\author{
GREEN KIM $^{1,2}$, TAE-HYOUN KIM ${ }^{3}$, EUN-HA HWANG ${ }^{1,2}$, KYU-TAE CHANG $^{2}$, \\ JUNG JOO HONG ${ }^{2}$ and JONG-HWAN PARK ${ }^{1}$ \\ ${ }^{1}$ Laboratory Animal Medicine, College of Veterinary Medicine, Chonnam National University, Gwangju 61186; \\ ${ }^{2}$ National Primate Research Center, Korea Research Institute of Bioscience and Biotechnology, Cheongju, \\ Chungcheongbuk 28116, Republic of Korea; ${ }^{3}$ Department of Microbiology and Immunology, \\ David H. Smith Center forVaccine Biology and Immunology, University of Rochester, Rochester, NY 14642, USA
}

Received October 5, 2016; Accepted March 3, 2017

DOI: 10.3892/ol.2017.6169

\begin{abstract}
Human gastric adenocarcinoma (AGS) is one of the most common types of malignant tumor and the third-leading cause of tumor-associated mortality worldwide. Withaferin A (WA), a steroidal lactone derived from Withania somnifera, exhibits antitumor activity in a variety of cancer models. However, to the best of our knowledge, the direct effect of WA on AGS cells has not previously been determined. The present study investigated the effects of WA on the proliferation and metastatic activity of AGS cells. WA exerted a dose-dependent cytotoxic effect on AGS cells. The effect was associated with cell cycle arrest at the G2/M phase and the expression of apoptotic proteins. Additionally, WA treatment resulted in a decrease in the migration and invasion ability of the AGS cells, as demonstrated using a wound healing assay and a Boyden chamber assay. These results indicate that WA directly inhibits the proliferation and metastatic activity of gastric cancer cells, and suggest that WA may be developed as a drug for the treatment of gastric cancer.
\end{abstract}

\section{Introduction}

Human gastric adenocarcinoma (AGS), one of the most common types of malignant neoplasm, is derived from the

Correspondence to: Dr Jung Joo Hong, National Primate Research Center, Korea Research Institute of Bioscience and Biotechnology, 30 Yeongudanji Street, Ochang, Chungwon, Cheongju, Chungcheongbuk 28116, Republic of Korea

E-mail: hong75@kribb.re.kr

Dr Jong-Hwan Park, Laboratory Animal Medicine, College of Veterinary Medicine, Chonnam National University, 77 Yongbong Street, Bukgu, Gwangju 61186, Republic of Korea

E-mail: jonpark@jnu.ac.kr

Key words: withaferin A, gastric cancer, proliferation, apoptosis, cell cycle arrest, migration glandular epithelium of the gastric mucosa $(1,2)$. Although chemotherapy is the primary treatment for gastric cancer, the toxic side effects and low efficacy of existing chemotherapeutic drugs remain a matter of concern (3). Therefore, studies to identify other potential anticancer agents and novel therapeutic approaches, including natural compounds, are important (4). For example, the plants used in traditional medicine are comparatively safe and cost-effective; their potential as alternatives to existing chemotherapeutic drugs should be investigated.

Withania somnifera (winter cherry) and active constituents derived from this plant have been used extensively in the traditional medicine of south Asia (5). Withaferin A (WA), a bioactive withanolide compound isolated from this plant, possibly contributes to the therapeutic effects of $W$. somnifera, particularly against cancer (6). Indeed, WA has been demonstrated to produce antitumorigenic effects in multiple cancer cell lines, including breast, prostate and lung cancer cells (7-9). Senthil et al (10) recently reported that an extract from $W$. somnifera inhibits the proliferation of AGS cells by inducing apoptosis and cell cycle arrest. Furthermore, we have recently reported that WA efficiently decreased pro-inflammatory processes in gastric epithelial cells, as well as immune cells, in response to Helicobacter pylori $(11,12)$, which serves a pivotal role in the high incidence of gastric cancer (2). However, a complete understanding of the antitumor effects of WA in gastric cancer remains to be achieved. Therefore, in the present study, the cell proliferation, apoptosis, cell cycle regulation and migration/invasion in AGS cells in response to WA treatment were examined, and the potential therapeutic effects of WA in AGS were further characterized.

\section{Materials and methods}

Cell culture and WA. AGS human gastric epithelial cells were purchased from the Korean Cell Line Bank (Seoul, Korea) and cultured with RPMI medium (Welgene, Inc., Daegu, Korea) containing $10 \%$ fetal bovine serum (FBS; Corning Incorporated, Corning, NY, USA) and penicillin/streptomycin in a $5 \% \mathrm{CO}_{2}$ incubator at $37^{\circ} \mathrm{C}$. WA was purchased from 
Sigma-Aldrich; Merck KGaA (Darmstadt, Germany). WA was dissolved in dimethyl sulfoxide (DMSO; Sigma-Aldrich; Merck KGaA) for use.

MTT assay. An MTT assay was performed to determine the cytotoxicity of WA in AGS cells. Cells $\left(1 \times 10^{4}\right.$ cells/well) were seeded in $200 \mu \mathrm{l}$ complete culture medium (RPMI medium with $10 \%$ FBS and penicillin/streptomycin) in 48 -well plates and incubated overnight at $37^{\circ} \mathrm{C}$. The cells were then incubated with different concentrations of WA $(0,0.5,1,2.5$ or $5 \mu \mathrm{M})$ for $24 \mathrm{~h}$. Each well was washed with PBS twice and then $200 \mu \mathrm{l}$ MTT $(4 \mathrm{mg} / \mathrm{ml})$ was added. Following a $4 \mathrm{~h}$ incubation at $37^{\circ} \mathrm{C}$, the MTT solution was removed and $200 \mu 1$ DMSO was added. The plates were agitated for $5 \mathrm{~min}$ to dissolve formazan crystals. The optical density (OD) values were determined at $570 \mathrm{~nm}$ using an ELISA plate reader (Epoch; BioTek Instruments, Inc., Winooski, VT, USA). Experiments were performed in triplicate with identical conditions.

Annexin V-fluorescein isothiocyanate (FITC)/propidium iodide (PI) double-staining assay. An Annexin V-FITC/PI double-staining assay was performed to analyze cell death in WA-treated AGS cells. Cells were seeded in complete culture medium at a density of $5 \times 10^{4}$ cells $/ \mathrm{ml}$ into a $60-\mathrm{ml}$ dish and incubated overnight. The cells were incubated with various concentrations of WA $(0,1,2.5$ and $5 \mu \mathrm{M})$ for 6 or $18 \mathrm{~h}$ at $37^{\circ} \mathrm{C}$. The cells were stained using a FITC Annexin $\mathrm{V}$ apoptosis detection kit I (BD Pharmingen, San Diego, CA, USA) according to the manufacturer's protocol and immediately analyzed using flow cytometry (BD FACSCalibur; BD Biosciences, Franklin Lakes, NJ, USA). The proportions of cells in four stages, including live, early apoptosis, late apoptosis and necrotis, were calculated using CellQuest ${ }^{\mathrm{TM}}$ Pro software (version 5.1; BD Biosciences, San Jose, CA, USA).

Western blotting. AGS cells were harvested, washed twice with PBS and lysed in a buffer containing 1\% Nonidet-P40 supplemented with protease inhibitors (complete Mini EDTA-free; Roche Applied Science, Mannheim, Germany) and $2 \mathrm{mM}$ dithiothreitol on ice. The extracted protein concentration was determined using a protein assay kit (cat no. 500-0006; Bio-Rad Laboratories, Inc., Hercules, CA, USA). Lysates $(30 \mu \mathrm{g})$ were separated by 10,12 and $15 \%$ SDS-PAGE and transferred onto nitrocellulose membranes by electroblotting at constant voltage $(100 \mathrm{~V})$ for $90 \mathrm{~min}$. The membranes were blocked with 5\% skimmed milk at room temperature for $1 \mathrm{~h}$ and incubated overnight with primary antibodies against cleaved caspase-3 (1:1,000; cat. no. 9664; rabbit), caspase-7 (1:1,000; cat. no. 8438; rabbit) and caspase-9 $(1: 1,000$; cat. no. 7237; rabbit), B-cell lymphoma 2 (Bcl-2; 1:1,000; cat. no. 2872; rabbit), cleaved poly (ADP-ribose polymerase) (PARP) (1:1,000; cat. no. 5625; rabbit), cyclin B1 (1:1,000; cat. no. 4138; rabbit) (all Cell Signaling Technology, Inc., Danvers, MA, USA), and $\beta$-actin (1:1,000; cat. no. sc130656; rabbit; Santa Cruz Biotechnology, Inc., Dallas, TX, USA). Following incubation with secondary horseradish peroxidase-conjugated goat anti-rabbit (1:4,000; cat. no. sc2301; Santa Cruz Biotechnology, Inc.) or goat anti-mouse IgG (1:2,000; cat. no. sc2031; Santa Cruz Biotechnology, Inc.) antibodies for $2 \mathrm{~h}$ at room temperature. Proteins were detected with SuperSignal ${ }^{\text {TM }}$ West Pico

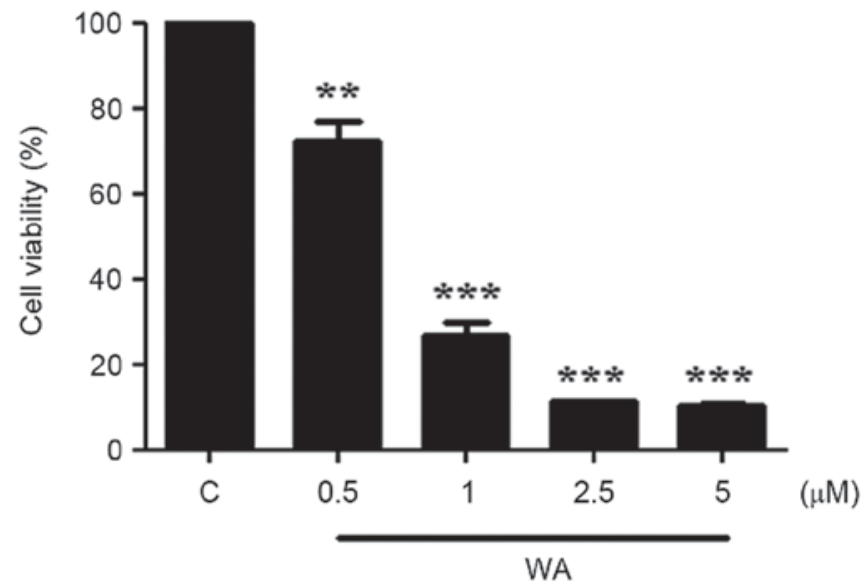

Figure 1. WA inhibits the viability of AGS cells. The viability of AGS cells was determined using an MTT assay. Cell viability was observed following treatment with various concentrations of WA $(0,0.5,1,2.5$ and $5 \mu \mathrm{M})$ for $24 \mathrm{~h}$. Results are presented as the mean \pm standard error of the mean $(n=3)$. ${ }^{* * *} \mathrm{P}<0.001 ;{ }^{* * *} \mathrm{P}<0.0001$ vs. $0 \mu \mathrm{M}$ group. WA, withaferin $\mathrm{A}$; AGS, gastric adenocarcinoma.

chemiluminescent substrate (Thermo Fisher Scientific, Inc., Waltham, MA, USA). Bands were visualized by exposing the blots onto CP-BU film (Agfa HealthCare NV, Mortsel, Belgium).

Cell cycle analysis. To perform cell cycle analysis, AGS cells were seeded in complete culture medium at a density of $5 \times 10^{5}$ cells $/ \mathrm{ml}$ in 6 -well plates and incubated overnight at $37^{\circ} \mathrm{C}$. The cells were then treated with $0,1,2.5$ or $5 \mu \mathrm{M}$ WA for $12 \mathrm{~h}$ at $37^{\circ} \mathrm{C}$. Following the incubation, cells were harvested with trypsin and fixed with $50 \%$ ethanol overnight at $-20^{\circ} \mathrm{C}$. The cells were washed with ice-cold PBS and incubated in PBS containing $50 \mu \mathrm{g} / \mathrm{ml} \mathrm{PI}$ and $100 \mu \mathrm{g} / \mathrm{ml}$ RNase A solution (both from Sigma-Aldrich; Merck KGaA) for $30 \mathrm{~min}$ at $37^{\circ} \mathrm{C}$ in the dark, followed by flow cytometric analysis (BD FACSCalibur; BD Biosciences). Cell cycle distribution (G1/G0, S and G2/M) was determined using CellQuest ${ }^{\mathrm{TM}}$ Pro software.

In vitro wound healing assay. An in vitro wound healing assay of AGS cells was performed at various time points, as described previously (13-15). Briefly, cells were plated in 6-well plates and grown to $100 \%$ confluency. Following the creation of a wound by scraping with a pipette tip, the cells were washed with PBS, treated with $0,10,100$ or $500 \mu \mathrm{M}$ WA in complete culture medium, and subsequently incubated at $37^{\circ} \mathrm{C}$ for $0,24,48$ or $56 \mathrm{~h}$. Cells were imaged at each time point with an IX51 widefield microscope (Olympus Corporation, Tokyo, Japan) at $\mathrm{x} 5$ magnification with an Orca ER charge-coupled device camera (Hamamatsu Photonics K.K., Hamamatsu, Japan).

Boyden chamber assay (invasion assay). The Boyden chamber technique was used to evaluate the invasion activity of AGS cells. The cells were seeded in complete culture medium at a density of $1 \times 10^{5}$ cells $/ \mathrm{ml}$ in a $60 \mathrm{ml}$ dish, incubated overnight at $37^{\circ} \mathrm{C}$ and subsequently treated with $0,1,2.5$ or $5 \mu \mathrm{M}$ WA for $24 \mathrm{~h}$ at $37^{\circ} \mathrm{C}$. Briefly, $27 \mu \mathrm{l}$ RPMI medium containing $10 \%$ FBS was added to the lower chambers. A collagen-coated 
A

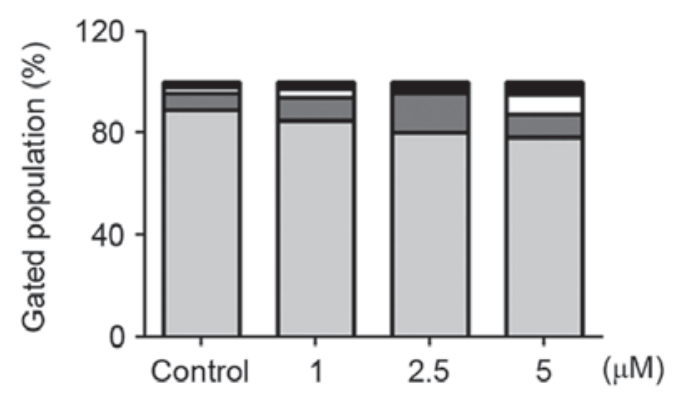

B

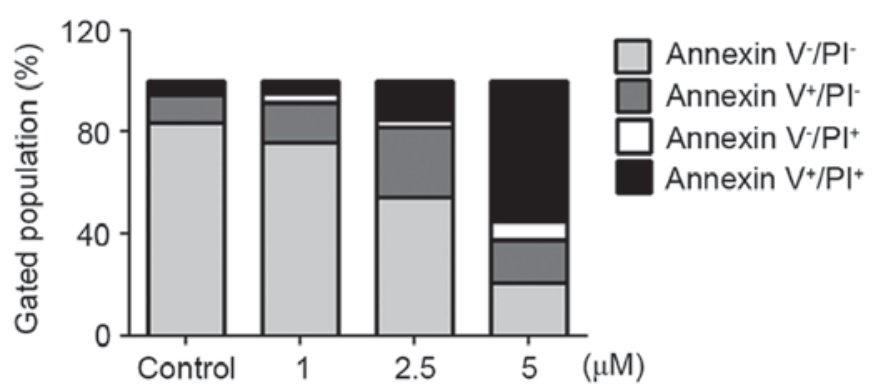

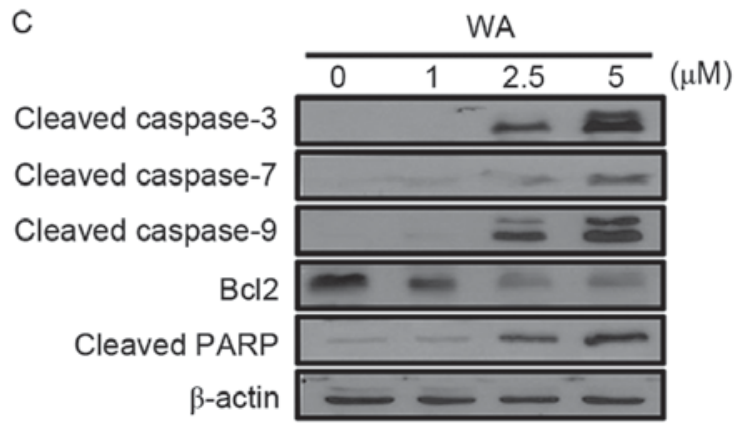

Figure 2. WA inhibits the growth of AGS cells by inducing apoptosis. The apoptotic status of AGS cells after (A) $6 \mathrm{~h}$ and (B) $18 \mathrm{~h}$ was evaluated using Annexin V-fluorescein isothiocyanate/propidium iodide double-staining method in flow cytometry. (C) Cellular protein was harvested at $6 \mathrm{~h}$ and the amounts of cleaved caspase-3, -7 and -9, PARP, Bcl-2, and $\beta$-actin were determined by western blotting. WA, withaferin A; AGS, gastric adenocarcinoma; PARP, poly(ADP-ribose) polymerase.

membrane with $8 \mu \mathrm{m}$ pores (Neuro Probe, Inc., Gaithersburg, MD, USA) was placed on top of the lower chambers. AGS cells $\left(1.8 \times 10^{6}\right.$ cells/well $)$ were added to the upper chambers and incubated for $6 \mathrm{~h}$ at $37^{\circ} \mathrm{C}$. The cells remaining on the upper side of the membrane were carefully removed using a cotton swab and stained using the Diff-Quick staining kit (Siemens Healthcare GmbH, Erlangen, Germany). The stained cells were counted manually at x100 magnification using a light microscope.

Statistical analysis. All experiments were performed at least in triplicate. Results were expressed as the mean \pm standard error of the mean. All statistical analyses (including a paired student's t-test and a one-way analysis of variance with a Bonferroni post hoc test) were performed using GraphPad Prism (version 5.00; GraphPad Software, Inc., La Jolla, CA, USA). $\mathrm{P}<0.01$ was considered to indicate a statistically significant difference.

\section{Results}

Treatment with WA results in a dose-dependent inhibition of AGS cell growth. The viability of AGS cells treated with WA was determined using the MTT assay. Cells $\left(1 \times 10^{4}\right.$ cells/well in a 48 -well plate) were exposed to various concentrations $(0,0.5$, $1,2.5$, and $5.0 \mu \mathrm{M}$ ) of WA for $24 \mathrm{~h}$. The proportion of viable cells was significantly decreased at the lowest concentration of WA treatment $(0.5 \mu \mathrm{M}, \mathrm{P}<0.01$; Fig. 1$)$. The half-maximal inhibitory concentration of WA in AGS cells at $24 \mathrm{~h}$ was $0.75 \pm 0.03 \mu \mathrm{M}$. At concentrations $>1 \mu \mathrm{M}$, a more significant decrease in cell viability was observed $(\mathrm{P}<0.001$; Fig. 1$)$. The data indicate that WA exerted a significant inhibitory effect on AGS cell proliferation.

WA inhibits the viability of AGS cells by inducing apoptosis. To determine whether the decreased viability was due to apoptosis in WA-treated AGS cells, an Annexin V-FITC/PI double-staining assay was performed for the identification of early and late apoptotic cells. As demonstrated in Fig. 2A $(6 \mathrm{~h})$ and $\mathrm{B}(18 \mathrm{~h})$, an increase in the frequency of Annexin V-positive cells was observed with increasing concentration of WA (at 6 and $18 \mathrm{~h}$ time points), compared with the control (Fig. 2A and B). The rate of apoptosis, including early (Annexin $\mathrm{V}^{+} / \mathrm{PI}^{-}$) and late (Annexin $\mathrm{V}^{+} / \mathrm{PI}^{+}$) stages, for each WA dose was increased compared with untreated cells (Fig. 2A and B). The proportion of early and late apoptotic cells increased in a WA dose-dependent manner (Fig. 2A and B). To understand the apoptotic events in WA-treated AGS cells, cleaved caspase-3, -7 and -9 , and PARP were examined as pro-apoptotic markers, and Bcl-2 was examined as an anti-apoptotic marker. Cleaved caspase-3, -7 and -9, and PARP proteins expression was most evident at 2.5 and $5 \mu \mathrm{M}$ WA, whereas Bcl-2 was decreased (Fig. 2C). This result suggests that WA-treated AGS cells undergo cell death via activation of caspases, PARP cleavage and the loss of Bcl-2, which is associated with apoptosis.

WA leads to G2/M cell cycle arrest in AGS cells. Cell cycle arrest is a key mechanism involved in the induction of cell growth inhibition (16). To test whether WA affects the cell cycle progression of AGS cells, cell cycle distribution analysis was performed with PI staining. AGS cells were treated with $0,1,2.5$ or $5 \mu \mathrm{M}$ WA for $12 \mathrm{~h}$. Compared with the negative 
A

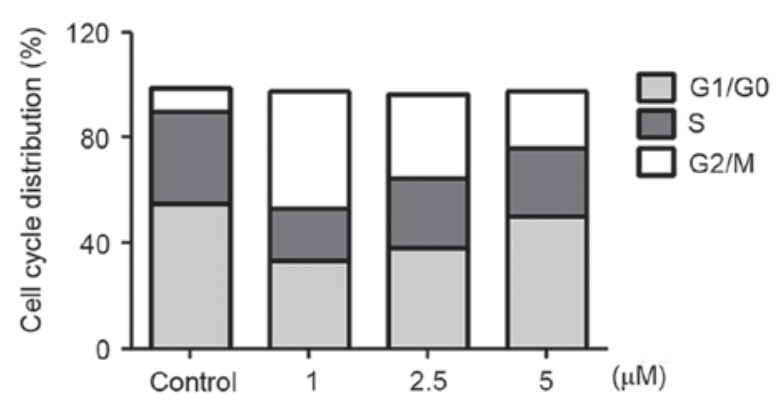

B

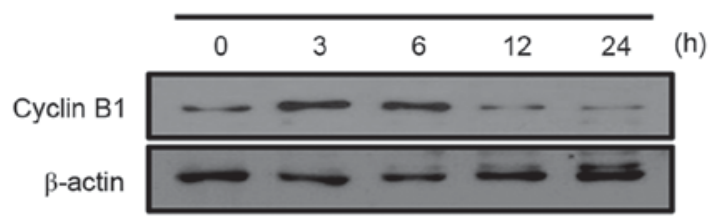

Figure 3. WA induces $\mathrm{G} 2 / \mathrm{M}$ cell cycle arrest by decreasing the expression of the cell cycle regulatory protein cyclin B1 in AGS cells. (A) The effect of WA on cell cycle distribution in AGS cells was evaluated using a propidium iodide staining assay. Results indicate the proportion of cells in each phase following treatment with WA $(0,1,2.5$ or $5 \mu \mathrm{M})$ for $12 \mathrm{~h}$. (B) The expression of cyclin B1 following $2.5 \mu \mathrm{M}$ WA treatment of AGS cells was detected using western blot analysis at various time points $(0,3,6,12$ and $24 \mathrm{~h})$. Data are representative of three independent experiments. WA, withaferin A; AGS, gastric adenocarcinoma.

control $(9.02 \%)$, WA treatment resulted in an increase in the proportion of $\mathrm{G} 2 / \mathrm{M}$ cells to $43.96,31.67$ and $21.82 \%$ in cells treated with $1,2.5$ and $5 \mu \mathrm{M}$ of WA for $12 \mathrm{~h}$, respectively (Fig. 3A). This phase shift was most marked at lower concentrations of WA treatment. WA-treated cells exhibited lower proportions of $\mathrm{G} 1 / \mathrm{G} 0$ cells $(33.5 \%$ at $1 \mu \mathrm{M}, 38.04 \%$ at $2.5 \mu \mathrm{M}$ and $50.08 \%$ at $5 \mu \mathrm{M})$ compared with untreated cells $(55.05 \%$; Fig. 3A). Similar to the effects on the proportion of cells in G1/G0 phase, WA treatment also resulted in a decrease in the proportion of cells in $\mathrm{S}$ phase (Fig. 3A). These results suggest that WA leads specifically to a $\mathrm{G} 2 / \mathrm{M}$ phase cell cycle arrest, accounting for the inhibition of proliferation in AGS cells. Moreover, an evident decrease in the expression of Cyclin B1 at $2.5 \mu \mathrm{M}$ WA treatment for 12 or $24 \mathrm{~h}$ was identified (Fig. 3B), which may cause the inhibition of G2/M progression (17). These data suggest that WA has an inhibitory effect on cell cycle progression, thereby resulting in the reduction of proliferation of AGS cells.

WA reduces the migration and invasion activity of AGS cells in vitro. The migratory and invasive abilities of AGS cells treated with WA were evaluated using an in vitro wound healing assay and a Boyden chamber assay. WA treatment tended to inhibit the migration of cells towards the wound at earlier time points (between 24 and $48 \mathrm{~h}$ ) and the difference compared with the extent of cell migration observed in the untreated cells was statistically significant at $56 \mathrm{~h}(\mathrm{P}<0.01$, $\mathrm{n}=3$; Fig. 4A and B). In the Boyden chamber assay, it was identified that AGS cells treated with $1,2.5$ or $5 \mu \mathrm{M}$ WA exhibited a significant decrease in invasive ability compared

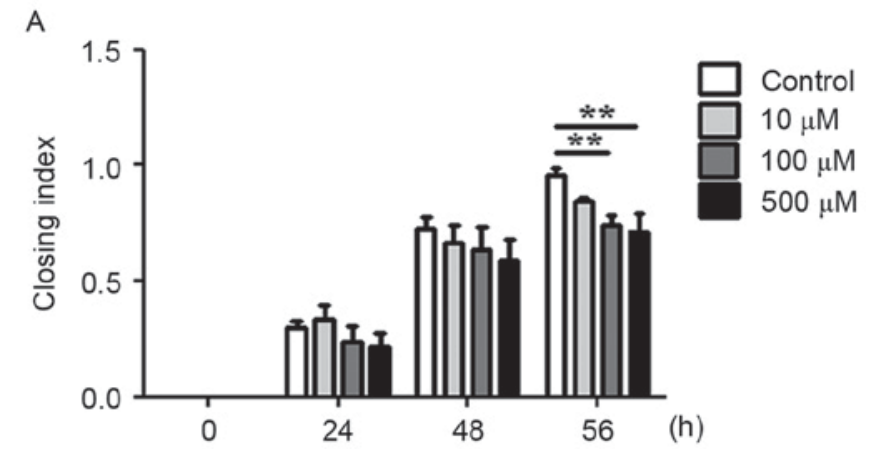

B

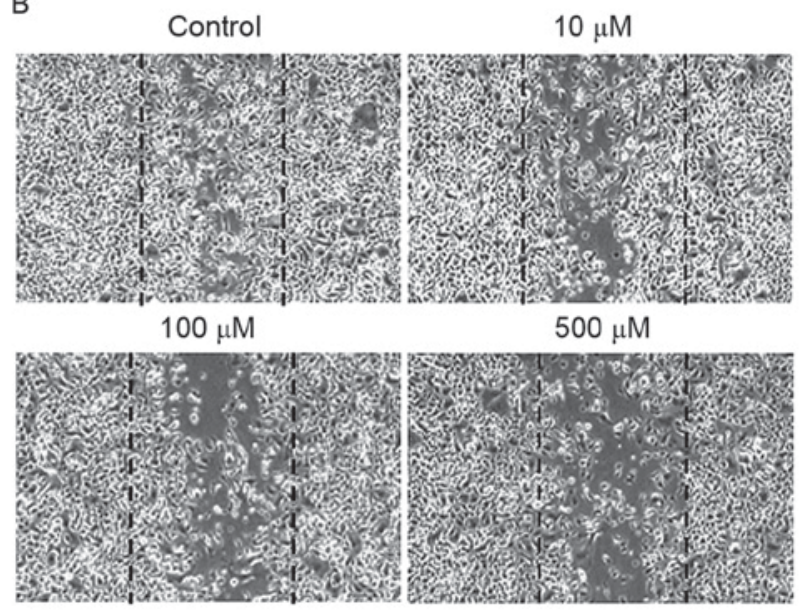

Figure 4. WA decreases the migration activity of AGS cells in a wound-healing assay. The migratory ability of AGS cells was evaluated using a wound-healing assay. (A) Cell migration was quantified 0, 24, 48 and $56 \mathrm{~h}$ after WA treatment at various concentrations. (B) Representative images (x5 magnification) of the wound healing assay for AGS cells treated with 0 , 10,100 and $500 \mu \mathrm{M}$ WA for $56 \mathrm{~h} .{ }^{* *} \mathrm{P}<0.01 ; \mathrm{n}=3$.

with untreated cells at $24 \mathrm{~h}$ (Fig. 5A and B), suggesting that WA has an inhibitory effect on the migratory and invasive capabilities of AGS cells.

\section{Discussion}

The aim of the present study was to assess the effects of WA on human AGS cells. WA, isolated from W. somnifera, has been ascribed therapeutic properties and its antitumor effects against various types of cancer have been reported (6). Previous studies have demonstrated that WA inhibited the growth of cancer cells, including cutaneous melanoma (18), ovarian cancer (19), prostate cancer (8) and leukemia (4) cells. Multiple molecular mechanisms underlying the antitumor activity of WA have been reported. Reactive oxygen species serve a role in the pro-apoptotic effect of WA in various types of cancer, including leukemia (20) and renal cancer (21). Proteasome inhibition, the induction of endoplasmic reticulum stress, downregulation of Akt serine/threonine kinase phosphorylation and the downregulation of Janus kinase/signal transducer and activator of transcription 3 signaling are also suggested to contribute to cancer cell apoptosis following WA treatment $(4,22,23)$. Transcription factors, including nuclear factor $-\kappa \mathrm{B}(\mathrm{NF}-\kappa \mathrm{B})$ and mitogen-activated protein kinases, contribute to WA-mediated induction of apoptosis of 


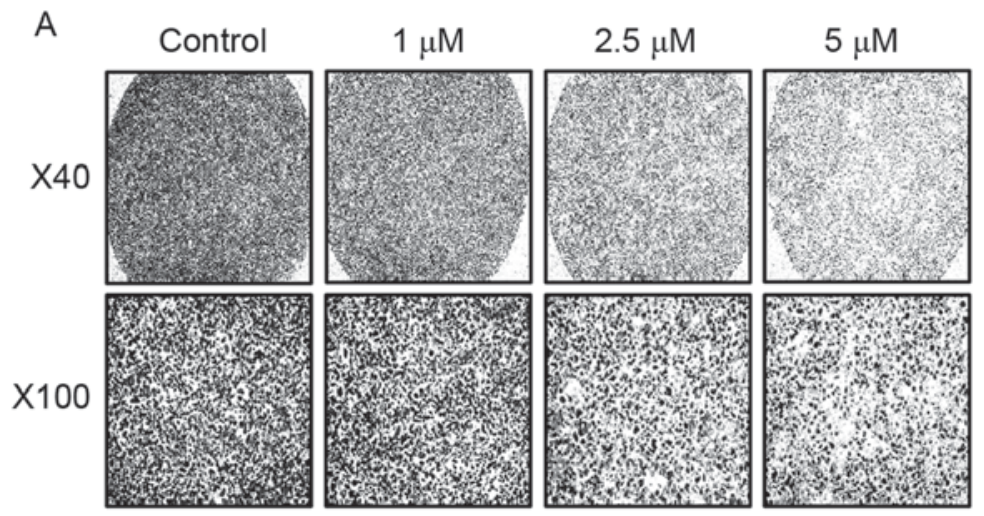

B

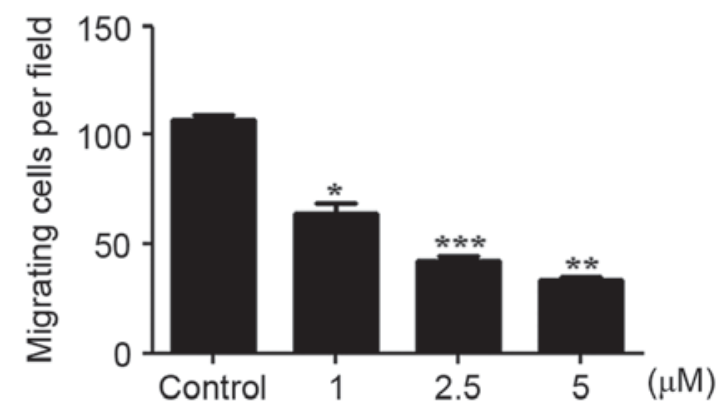

Figure 5. WA inhibits the invasive activity of AGS cells in vitro. (A) The effect of WA on the invasive ability of AGS cells treated with $0,1,2.5$ and $5 \mu \mathrm{M}$ WA for $24 \mathrm{~h}$ was evaluated using a Boyden chamber assay. Representative images of the Boyden chamber assay were captured at x40 and x $100 \mathrm{magnification}$. (B) Cell invasion was quantified following treatment with various concentrations of WA for $24 \mathrm{~h}$. Results are presented as the mean \pm standard error of the mean $(\mathrm{n}=3) .{ }^{*} \mathrm{P}<0.01,{ }^{* *} \mathrm{P}<0.001 ;{ }^{* * *} \mathrm{P}<0.0001$ vs. control.

leukemia $(4,24)$, glioblastoma (25) and breast cancer (26). The antitumor effects of WA on human AGS were not previously studied, although $W$. somnifera leaf and root extract have been assessed for their effect on AGS cells (10). In the present study, it was identified that apoptosis was significantly increased in AGS cells treated with WA. As expected, WA treatment of AGS cells upregulated the expression of the initiator (caspase-9) and effector (capase-3 and -7) caspases, which cleave PARP protein. In addition, WA-treated cells exhibited relatively decreased Bcl-2 levels, which promotes gastric cancer cell survival. Indeed, the downregulation of Bcl-2 has been previously associated with the mechanisms underlying the anti-proliferative effect of WA in a variety of cultured cell types $(18,21)$.

Apoptosis induced by WA may be associated with cell cycle arrest at different phases in cancer cell lines. For example, WA was demonstrated to cause the arrest of cell cycle at the sub-G1 phase in renal carcinoma cells (21), and in the G2/M phase in leukemia (27), uveal melanoma cells (28), breast cancer cells (29) and ovarian carcinoma cells (19). The results of the present study indicated that WA treatment caused G2/M cell cycle arrest in AGS cells, thus delaying the progression of the cells toward mitosis. This G2/M phase shift was more pronounced at lower WA concentrations, whereas apoptotic events were increased at higher WA concentration (Figs. 2 and 3) WA-treated AGS cells also exhibited depleted cyclin $\mathrm{B} 1$, which is required to promote $\mathrm{G} 2 / \mathrm{M}$ transition (Fig. 3B). The alteration in cyclin B1 has been associated with the induction of cell cycle arrest in the presence of WA; WA was previously demonstrated to decrease the activity of cyclin B1-dependent kinase 1 (Cdk1) and complex formation between cyclin B1 and Cdk1 in cancer cells $(30,31)$. In human breast cancer and ovarian carcinoma cells, WA treatment resulted in the downregulation of cell division cycle $25^{\circ} \mathrm{C}$, which activates cyclin B1-Cdk1 complexes $(19,31)$. These data suggest that apoptosis induced by WA may be initiated by $\mathrm{G} 2 / \mathrm{M}$ phase cell cycle arrest due to the change in the levels of cyclin B1.

Invasion and metastasis are hallmarks of cancer development. WA has been reported to inhibit the metastatic behavior of human cancer cells (32). In the in vitro setting of the present study, AGS cell migration and invasion were markedly inhibited by WA. Vimentin and matrix metalloproteinases (MMPs) may be potential target molecules for WA in AGS cells, although these were not examined in the present study. Vimentin, the level of which is associated with cell metastasis and motility in patients with gastric cancer (33), was expressed at a high level in the metastatic gastric cancer cell line TMC-1, and at a low level in the non-invasive gastric cancer cell line SC-M1 (34). WA directly binds to the cysteine residues of vimentin to modify the domain structure of vimentin (35), resulting in the impairment of the function of this protein in gastric cancer (33). In addition to vimentin, MMPs are associated with gastric cancer invasion and metastasis, and are used as markers to assess the progression of gastric cancer (36). In gastric cancer cells, MMP-2 and MMP-9 serve important roles in cancer infiltration, and MMP-2 and MMP-9 expression was demonstrated to be associated with the progression of the tumor (37). WA blocks MMP-9 activity in metastatic cancer cell lines (38), suggesting a possible explanation for WA-induced inhibition of metastasis in AGS cells. Further investigation is warranted, however, to clarify the role of vimentin and MMPs in the pharmacological activity of WA in AGS cells.

The inflammatory response is one of the major factors promoting the initiation and progression of gastric cancer (39). In particular, H. pylori infection may induce gastric cancer by enhancing the inflammatory response (40). In addition, upregulation of interleukin 8 , vascular endothelial growth factor, angiogenin, urokinase-type plasminogen activator and MMP-9 genes by H. pylori was reported to regulate the metastasis and the invasion of gastric cancer cells $(41,42)$. Recently, our group reported that WA inhibited the activation of NF- $\mathrm{KB}$ and pro-inflammatory cytokine production in gastric epithelial and immune cells infected with $H$. pylori $(11,12)$. Therefore, there is evidence to suggest that the anti-inflammatory effects of WA may hinder the progression of gastric adenocarcinogenesis.

To the best of our knowledge, the results of the present study demonstrate for the first time that WA inhibits human AGS cell growth by the induction of G2/M cell cycle arrest and apoptosis. WA also suppressed AGS cell migration and 
invasion. These results provide support for the development of WA as a novel therapeutic strategy against gastric cancer.

\section{Acknowledgements}

The present study was supported by the Program for Basic Research in Science and Engineering, funded by the National Research Foundation of Korea in the Ministry of Science, Information and Communications Technology and Future Planning of Korea (grant no. NRF-2015R1A2A2A01002360) and a grant from the Korea Research Institute of Bioscience and Biotechnology (grant no. KGM4241642).

\section{References}

1. Ferlay J, Shin HR, Bray F, Forman D, Mathers C and Parkin DM: Estimates of worldwide burden of cancer in 2008: GLOBOCAN 2008. Int J Cancer 127: 2893-2917, 2010.

2. Fock KM: Review article: The epidemiology and prevention of gastric cancer. Aliment Pharmacol Ther 40: 250-260, 2014.

3. Dai ZJ, Gao J, Ji ZZ, Wang XJ, Ren HT, Liu XX, Wu WY, Kang HF and Guan HT: Matrine induces apoptosis in gastric carcinoma cells via alteration of Fas/FasL and activation of caspase-3. J Ethnopharmacol 123: 91-96, 2009.

4. Oh JH, Lee TJ, Kim SH, Choi YH, Lee SH, Lee JM, Kim YH, Park JW and Kwon TK: Induction of apoptosis by withaferin A in human leukemia U937 cells through down-regulation of Akt phosphorylation. Apoptosis 13: 1494-1504, 2008.

5. Mirjalili MH, Moyano E, Bonfill M, Cusido RM and Palazón J: Steroidal lactones from Withania somnifera, an ancient plant for novel medicine. Molecules 14: 2373-2393, 2009.

6. Palliyaguru DL, Singh SV and Kensler TW: Withania somnifera: From prevention to treatment of cancer. Mol Nutr Food Res 60: 1342-1353, 2016.

7. Hahm ER and Singh SV: Withaferin A-induced apoptosis in human breast cancer cells is associated with suppression of inhibitor of apoptosis family protein expression. Cancer Lett 334: 101-108, 2013.

8. Roy RV, Suman S, Das TP, Luevano JE and Damodaran C: Withaferin A, a steroidal lactone from Withania somnifera, induces mitotic catastrophe and growth arrest in prostate cancer cells. J Nat Prod 76: 1909-1915, 2013.

9. Cai Y, Sheng ZY, Chen Y and Bai C: Effect of Withaferin A on A549 cellular proliferation and apoptosis in non-small cell lung cancer. Asian Pac J Cancer Prev 15: 1711-1714, 2014.

10. Senthil K, Jayakodi M, Thirugnanasambantham P, Lee SC, Duraisamy P, Purushotham PM, Rajasekaran K, Nancy Charles S, Mariam Roy I, Nagappan AK, et al: Transcriptome analysis reveals in vitro cultured Withania somnifera leaf and root tissues as a promising source for targeted withanolide biosynthesis. BMC Genomics 16: 14, 2015.

11. Kim G, Kim TH, Kang MJ, Choi JA, Pack DY, Lee IR, Kim MG, Han SS, Kim BY, Oh SM, et al: Inhibitory effect of withaferin A on Helicobacter pylori-induced IL8 production and NFKB activation in gastric epithelial cells. Mol Med Rep 13: 967-972, 2016.

12. Kim JE, Lee JY, Kang MJ, Jeong YJ, Choi JA, Oh SM, Lee KB and Park JH: Withaferin A inhibits helicobacter pylori-induced production of IL-1 $\beta$ in dendritic cells by regulating NF- $\kappa \mathrm{B}$ and NLRP3 inflammasome activation. Immune Netw 15: 269-277, 2015.

13. Fejzo MS, Anderson L, Chen HW, Anghel A, Zhuo J, Anchoori R, Roden R and Slamon DJ: ADRM1-amplified metastasis gene in gastric cancer. Genes Chromosomes Cancer: Jun 6, 2015 (Epub ahead of print).

14. Lin SH and Shih YW: Antitumor effects of the flavone chalcone: Inhibition of invasion and migration through the FAK/JNK signaling pathway in human gastric adenocarcinoma AGS cells Mol Cell Biochem 391: 47-58, 2014.

15. Pal AD, Basak NP, Banerjee AS and Banerjee S: Epstein-Barr virus latent membrane protein-2A alters mitochondrial dynamics promoting cellular migration mediated by Notch signaling pathway. Carcinogenesis 35: 1592-1601, 2014.

16. King KL and Cidlowski JA: Cell cycle regulation and apoptosis. Annu Rev Physiol 60: 601-617, 1998.

17. Stark GR and Taylor WR: Control of the G2/M transition. Mol Biotechnol 32: 227-248, 2006.
18. Mayola E, Gallerne C, Esposti DD, Martel C, Pervaiz S, Larue L, Debuire B, Lemoine A, Brenner C and Lemaire C: Withaferin $\mathrm{A}$ induces apoptosis in human melanoma cells through generation of reactive oxygen species and down-regulation of $\mathrm{Bcl}-2$. Apoptosis 16: 1014-1027, 2011

19. Zhang X, Samadi AK, Roby KF, Timmermann B and Cohen MS: Inhibition of cell growth and induction of apoptosis in ovarian carcinoma cell lines $\mathrm{CaOV} 3$ and SKOV3 by natural withanolide Withaferin A. Gynecol Oncol 124: 606-612, 2012.

20. Malik F, Kumar A, Bhushan S, Khan S, Bhatia A, Suri KA, Qazi GN and Singh J: Reactive oxygen species generation and mitochondrial dysfunction in the apoptotic cell death of human myeloid leukemia HL-60 cells by a dietary compound withaferin A with concomitant protection by $\mathrm{N}$-acetyl cysteine. Apoptosis 12: 2115-2133, 2007.

21. Yang ES, Choi MJ, Kim JH, Choi KS and Kwon TK: Withaferin A enhances radiation-induced apoptosis in Caki cells through induction of reactive oxygen species, Bcl-2 downregulation and Akt inhibition. Chem Biol Interact 190: 9-15, 2011.

22. Um HJ, Min KJ, Kim DE and Kwon TK: Withaferin A inhibits JAK/STAT3 signaling and induces apoptosis of human renal carcinoma Caki cells. Biochem Biophys Res Commun 427: 24-29, 2012.

23. Choi MJ, Park EJ, Min KJ, Park JW and Kwon TK: Endoplasmic reticulum stress mediates withaferin A-induced apoptosis in human renal carcinoma cells. Toxicol In Vitro 25: 692-698, 2011.

24. Mandal C, Dutta A, Mallick A, Chandra S, Misra L, Sangwan RS and Mandal C: Withaferin A induces apoptosis by activating p38 mitogen-activated protein kinase signaling cascade in leukemic cells of lymphoid and myeloid origin through mitochondrial death cascade. Apoptosis 13: 1450-1464, 2008.

25. Grogan PT, Sleder KD, Samadi AK, Zhang H, Timmermann BN and Cohen MS: Cytotoxicity of withaferin A in glioblastomas involves induction of an oxidative stress-mediated heat shock response while altering Akt/mTOR and MAPK signaling pathways. Invest New Drugs 31: 545-557, 2013.

26. Hahm ER, Lee J and Singh SV: Role of mitogen-activated protein kinases and Mcl-1 in apoptosis induction by withaferin A in human breast cancer cells. Mol Carcinog 53: 907-916, 2014.

27. Okamoto S, Tsujioka T, Suemori SI, Kida J, Kondo T, Tohyama Y and Tohyama K: Withaferin A suppresses the growth of myelodysplasia and leukemia cell lines by inhibiting cell cycle progression. Cancer Sci 107: 1302-1314, 2016.

28. Samadi AK, Cohen SM, Mukerji R, Chaguturu V, Zhang X, Timmermann BN, Cohen MS and Person EA: Natural withanolide withaferin A induces apoptosis in uveal melanoma cells by suppression of Akt and c-MET activation. Tumour Biol 33: 1179-1189, 2012.

29. Antony ML, Lee J, Hahm ER, Kim SH, Marcus AI, Kumari V, Ji X, Yang Z, Vowell CL, Wipf P, et al: Growth arrest by the antitumor steroidal lactone withaferin $\mathrm{A}$ in human breast cancer cells is associated with down-regulation and covalent binding at cysteine 303 of $\beta$-tubulin. J Biol Chem 289: 1852-1865, 2014.

30. Munagala R, Kausar H, Munjal C and Gupta RC: Withaferin A induces p53-dependent apoptosis by repression of HPV oncogenes and upregulation of tumor suppressor proteins in human cervical cancer cells. Carcinogenesis 32: 1697-1705, 2011.

31. Stan SD, Zeng Y and Singh SV: Ayurvedic medicine constituent withaferin a causes G2 and M phase cell cycle arrest in human breast cancer cells. Nutr Cancer 60 (Suppl 1): S51-S60, 2008.

32. Thaiparambil JT, Bender L, Ganesh T, Kline E, Patel P, Liu Y, Tighiouart M, Vertino PM, Harvey RD, Garcia A and Marcus AI: Withaferin $\mathrm{A}$ inhibits breast cancer invasion and metastasis at sub-cytotoxic doses by inducing vimentin disassembly and serine 56 phosphorylation. Int J Cancer 129: 2744-2755, 2011.

33. Fuyuhiro Y, Yashiro M, Noda S, Kashiwagi S, Matsuoka J, Doi Y, Kato Y, Kubo N, Ohira M and Hirakawa K: Clinical significance of vimentin-positive gastric cancer cells. Anticancer Res 30: 5239-5243, 2010.

34. Chen YR, Juan HF, Huang HC, Huang HH, Lee YJ, Liao MY, Tseng CW, Lin LL, Chen JY, Wang MJ, et al: Quantitative proteomic and genomic profiling reveals metastasis-related protein expression patterns in gastric cancer cells. J Proteome Res 5: 2727-2742, 2006

35. Bargagna-Mohan P, Hamza A, Kim YE, Khuan Abby Ho Y, Mor-Vaknin N, Wendschlag N, Liu J, Evans RM, Markovitz DM, Zhan CG, et al: The tumor inhibitor and antiangiogenic agent withaferin A targets the intermediate filament protein vimentin. Chem Biol 14: 623-634, 2007. 
36. Shen $\mathrm{W}, \mathrm{Xi} \mathrm{H}$, Wei B and Chen L: The prognostic role of matrix metalloproteinase 2 in gastric cancer: A systematic review with meta-analysis. J Cancer Res Clin Oncol 140: 1003-1009, 2014.

37. Parsons SL, Watson SA, Collins HM, Griffin NR, Clarke PA and Steele RJ: Gelatinase (MMP-2 and -9) expression in gastrointestinal malignancy. Br J Cancer 78: 1495-1502, 1998.

38. Lee DH, Lim IH, Sung EG, Kim JY, Song IH, Park YK and Lee TJ: Withaferin A inhibits matrix metalloproteinase-9 activity by suppressing the Akt signaling pathway. Oncol Rep 30: 933-938, 2013

39. Rayburn ER, Ezell SJ and Zhang R: Anti-Inflammatory agents for cancer therapy. Mol Cell Pharmacol 1: 29-43, 2009.

40. Wroblewski LE, Peek RM Jr and Wilson KT: Helicobacter pylori and gastric cancer: Factors that modulate disease risk. Clin Microbiol Rev 23: 713-739, 2010.
41. Kitadai Y, Sasaki A, Ito M, Tanaka S, Oue N, Yasui W, Aihara M, Imagawa K, Haruma K and Chayama K: Helicobacter pylori infection influences expression of genes related to angiogenesis and invasion in human gastric carcinoma cells. Biochem Biophys Res Commun 311: 809-814, 2003.

42. Strowski MZ, Cramer T, Schäfer G, Jüttner S, Walduck A, Schipani E, Kemmner W, Wessler S, Wunder C, Weber M, et al: Helicobacter pylori stimulates host vascular endothelial growth factor-A (vegf-A) gene expression via MEK/ERK-dependent activation of Sp1 and Sp3. FASEB J 18: 218-220, 2004. 